\title{
Cost-Tailored Load Management for Power Quality in an Independent Power System as an Interdisciplinary Capstone Design Project
}

\author{
Herbert L. Hess \\ Electrical and Compute Engineering \\ University of Idaho \\ Moscow, Idaho
}

Abstract

An interdisciplinary undergraduate design team redesigns and builds a hybrid windpowerfossil fuel generation facility that provides electricity and water for an environmentally sensitive wilderness location. Students first develop objectives for quantity of power, quality of power, and practical maintenance. In addressing a host of cutting-edge technical issues, environmental constraints, and human factors, they find a way to meet their objectives. They propose a uniquely insightful design in such a way that the customer can tailor it based on cost, including intangible costs. Upon receiving the customer's tailored solution, the students build the system. Finally, they propose practical maintenance arrangements. The system successfully provides power and continues to do so.

Introduction

Isolated electric power systems for residential use are popular in the wilderness of the Pacific Northwest [1]. In the past, these have often been quite crude, providing just a few watts for basic needs. However, new residents bring much higher expectations. They want major appliances, lights, and delivery of water on the same electrical system that powers televisions and computers. They expect the same quality of power that the public utilities achieve. Of course, they prefer renewables, often combinations of solar, wind, and water power. In any event, no environmental harm is tolerated. Unfortunately, manufacturers and designers of these remote electrical systems are not equal to such high expectations.

In 1999, a homeowner commissioned an interdisciplinary student design team to

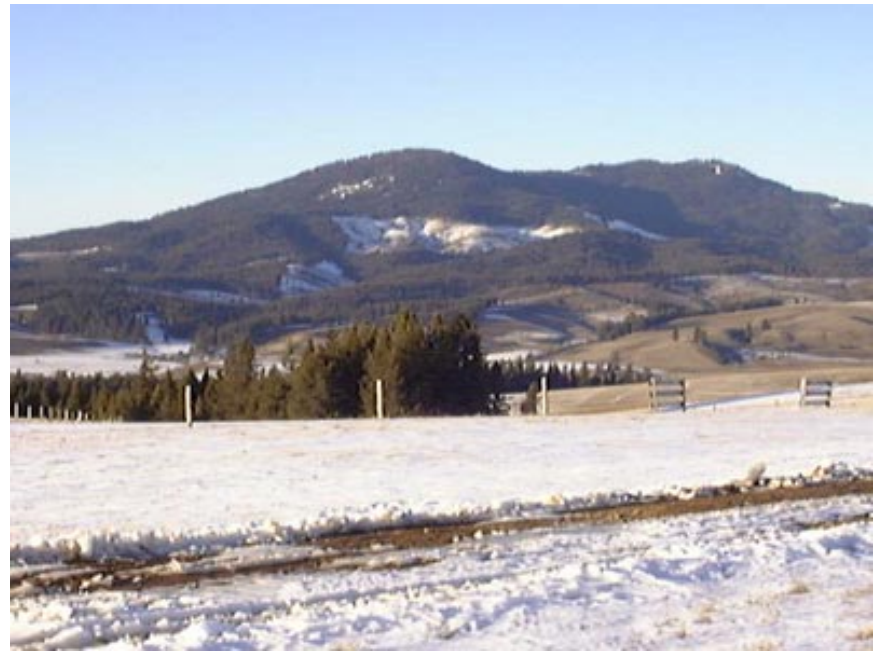

Figure 1. Wilderness Location Requiring Clean, Reliable Electric Power. 
redesign an isolated electrical power generation facility in the beautiful location shown in Figure 1. This paper reports how a team of four undergraduate engineering students, consisting of two Mechanical Engineers and two Electrical Engineers, successfully address this problem as a senior capstone design project. First, they assess the feasibility of the project. Defining the problem is the biggest hurdle. They find that addressing this problem is within the capability of the team as students. Second, investigating the necessary technical questions and cost issues, they design a uniquely creative solution to the problems of power quantity and power quality that they must solve. The degree to which the students incorporate human factors is new to problems of this nature. Third, they use a graduated cost methodology that is fundamental to structuring power quality problems. This allows the homeowner to tailor the solution based on the homeowner's own cost structure, tangible and intangible. In so doing, they gain customer ownership in the solution, the prerequisite to effective long-term maintenance. Fourth, with the approval of the customer, they build the system and test it thoroughly. Fifth, they create an operations guide and a user-friendly maintenance system. Finally, they post a website describing their engineering: a creative, entrepreneurial use of mechanical and electrical fundamentals, people skills, resource allocation, and common sense. They do all this in two semesters.

\section{Situation}

In 1999, a local doctor built a "straw bale" home on top of a windy hill several kilometers from Harvard, Idaho. For such remote locations, the cost of installing a radial electric distribution line far exceeds the cost of an isolated electric generation system. The site has plenty of wind, leading the doctor to install a "cookie cutter" windpower-fossil fuel generator system with lead-acid battery storage. This particular design provides for a family of four, so the contractor says. Passive solar design features of the house and a wood stove furnish most of the space heating. Propane provides the energy for hot water, cooking, and occasional space heating.

However, the system operates so poorly that the doctor considers abandoning it. Problems include the following:

1. Insufficient power for normal electrical loads. A diesel generator provides the lion's share of the electrical energy. Battery storage smooths out the supply, allowing the generator to operate in a more efficient on-off mode. However, the generator is too small. Automatic cycling of the generator, based on battery charge level, is unreliable.

2. Battery bank fails to provide the expected amount of energy. The undersized generator never fully charges the batteries. Inadequate temperature control of the battery enclosure significantly degrades its performance.

3. Failures of electronics used in the home appliances. The energy saving electronic features of the washer and dryer rarely work properly and finally fail altogether. The lights in the house flicker and cause the computer to reboots when the washer operates.

4. When the main water pump start, electrical service to the house seems to cease entirely for a second or so. Anything electronic reboots or fails. Lights dim or die. Even the vacuum cleaner hesitates. Most electrical loads recover, but some don't.

5. Confusing and differing opinions from consultants and trades people. Various trades people try to sell improvements for the system. Suggestions are piecemeal at best. Their ideas include adding more batteries, moving the batteries and inverter closer to the house, and installing larger electrical cable. Unfortunately, no one proposes an integrated solution. 
Feasibility Study

The four students in the design team first ask whether solving these problems is feasible, given their ability and resources. They find a fundamentally sound electrical system already in place, as diagrammed in Figure 2. The load is easy to identify and characterize. None of the wiring or circuit protection needs redesign.

The most obvious problem is an inverter-controller that ineffectively manages the flow of an inadequate amount energy production and storage. Some important technical problems in the inverter design also produce unacceptable power quality. Fortunately, the inverter-controller for this power system is flexible enough to accommodate a host of changes in energy management.

The students must organize a set of modifications and attach a cost to each item. Then the customer may pick and choose, tailoring a solution to her needs and her budget. Because this is the customer's home, any maintenance must easy to perform. In discussing these problems with the customer, the students identify three objectives:

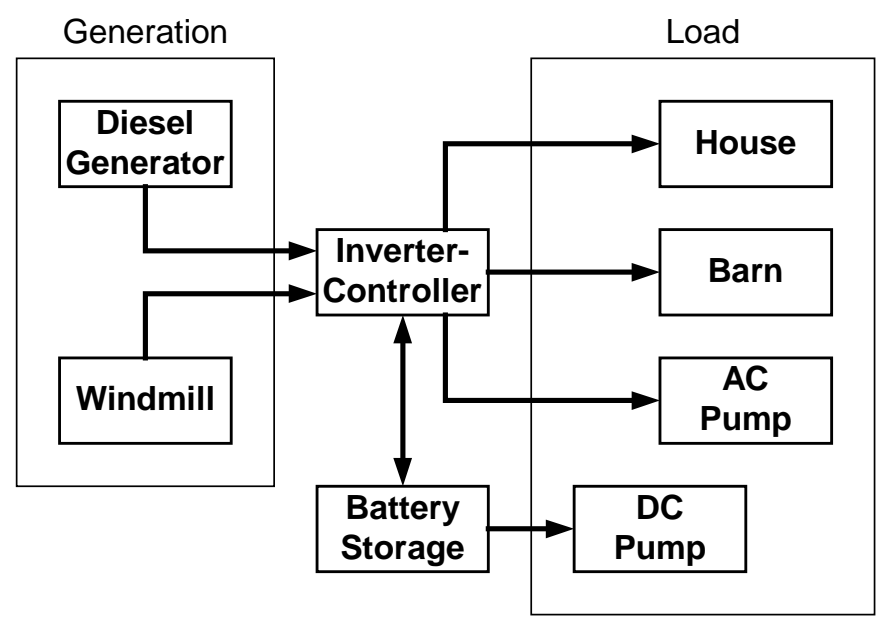

Figure 2. Structure of Existing Energy

Distribution System.

1. Provide sufficient quantity of power to meet the needs of the family.

2. Provide quality power sufficient for the system to function acceptably.

3. Document the entire system, not just the changes, for ease of maintenance.

Power Quantity

The first objective of the project is to provide sufficient quantity of power to meet the needs of the family. The students quickly identify two ways to do this: increase the quantity of available power and decrease the demand. Conservation is indeed more attractive than adding generation in this case. Reducing the number of charging cycles of the generator becomes a goal.

An energy use model reveals where the customer consumes energy. By accounting for each watt, an orderly set of improvements may become apparent. Therefore, the team drew Figure 3 to show how the load is distributed. From this, the team finds six possible improvements to recommend to the customer. In so doing, they identify the cost of each one as well.

1. Idle Load. Conservation is more than simply unplugging equipment when not in use. Even when turned off, audio-visual idle loads, e.g., an "instant-on" television, consume $9 \%$ of the average load. Pilotless ignition consumes $8 \%$ of the average load continually before warming a drop of water. The remedy for this is simple: use power strips with an on-off switch for all "plug-in" loads that consume energy in an idle state.

2. Water distribution. Water pumping consumes nearly $20 \%$ of the average load. The team's Mechanical Engineers found that the water system uses two pumps. A DC low flow, deep well submersible pump lifts water more than 60 meters from the well to two 4000-liter cisterns. An AC centrifugal pump pressurizes the water to both house and barn. The house 
is on the same level as the cisterns, but the barn is 20 meters below the cisterns. Though water for the house must be actively pressurized, the team's Mechanical Engineers calculate that gravity alone may provide adequate water pressure for the barn. This may save over half of the energy used by the AC pump and cycled it much less often. This improvement also yields important advantages for power quality, as explained in the next section of this paper.

3. Lights. Lighting is one-sixth of the average load. Two improvements reduce this significantly with minimal effort: replacing incandescent lights with compact fluorescent bulbs and reducing the amount of indirect lighting.

4. Inverter's idle load. In the inverter, a native automatic search mode minimizes power draw at no load. This feature reduces the inverter's idle load from 16 watts to 1 watt. Eliminating all idle loads allows the students to reap this dividend, but they must be good detectives to find it all. The electric fence charger for the horse corral and the telephone answering machine are the last loads to be identified and removed: a battery option may erase the former and centralized message service at the telephone company may replace the latter.

5. Battery operation conditions. Improving the quantity of energy storage is also important. Poorly performing batteries must be replaced. Because maintenance is a factor in battery demise, a practical maintenance schedule mitigates this problem for the long term, as explained later in this paper. An uninsulated box contains 24 lead-acid batteries. Because this box sits on a simple concrete floor over a 4000-liter water cistern, battery temperature is a nearly constant $20^{\circ} \mathrm{C}$ year-round. The team's Mechanical Engineers propose replacing this 
with an insulated box with auxiliary heat to maintain the batteries at an optimum $30^{\circ} \mathrm{C}$, increasing storage capacity by nearly $30 \%$. In the same design, they include passive ventilation and complete containment for a worstcase acid spill. The finished box is shown in Figure 4.

6. New windmill. Energy demand peaks in the winter for this site.

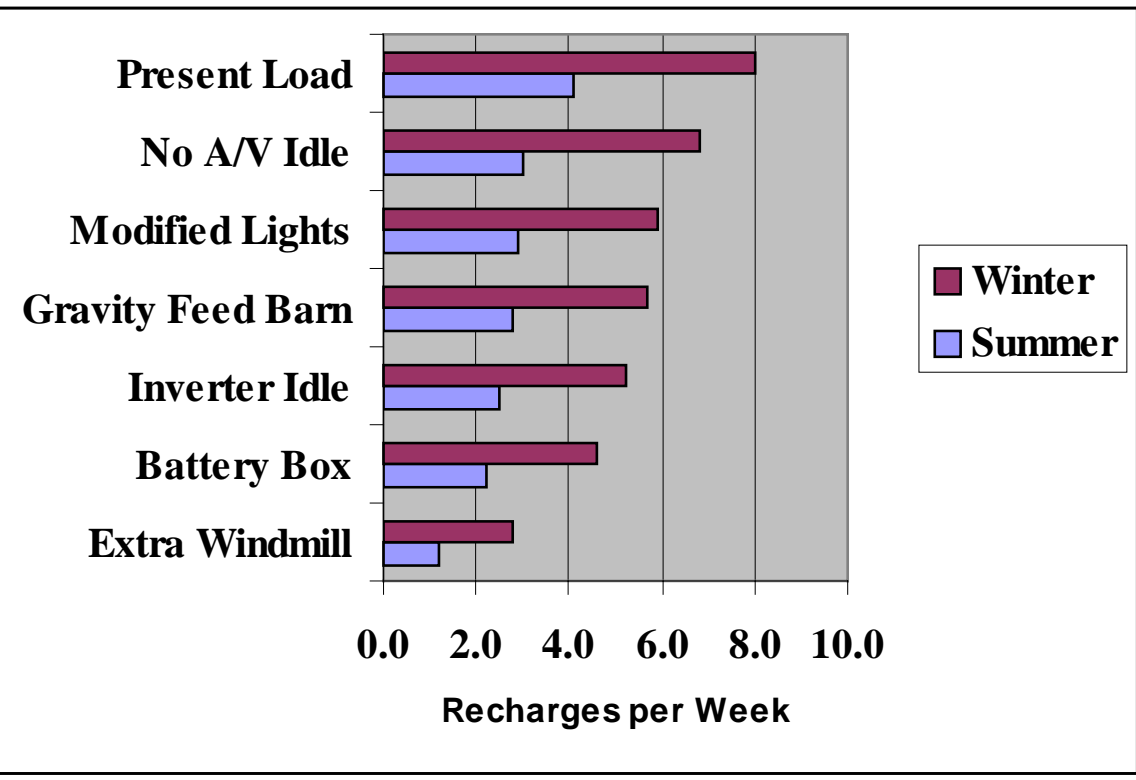

Fortunately, available wind energy is also Figure 5. Power Quantity Improvements. significantly greater during the winter. A study of the wind patterns reveals that another windmill may cut the remaining diesel generator load in half, saving a great deal of fuel. Details of the design are shown on the project's website [3].

The students express the results of their investigation in terms of the number of times that the batteries would have to be charged weekly. This is a metric that the homeowner easily understands. Initially, the energy requirements drain the batteries eight times per week in the winter and 4.1 times per week in the summer. The effect of each of the improvements is apparent in Figure 5. They are additive. The homeowner may use this data to help choose an attractive combination of improvements.

Of course, the customer is interested in the cost of these options. Some, such as eliminating the idle features of "plug-in" loads, are nearly free. Others have a significant payback period. A dollar cost, along with an expected payback period, is shown in Figure 6. Each option is
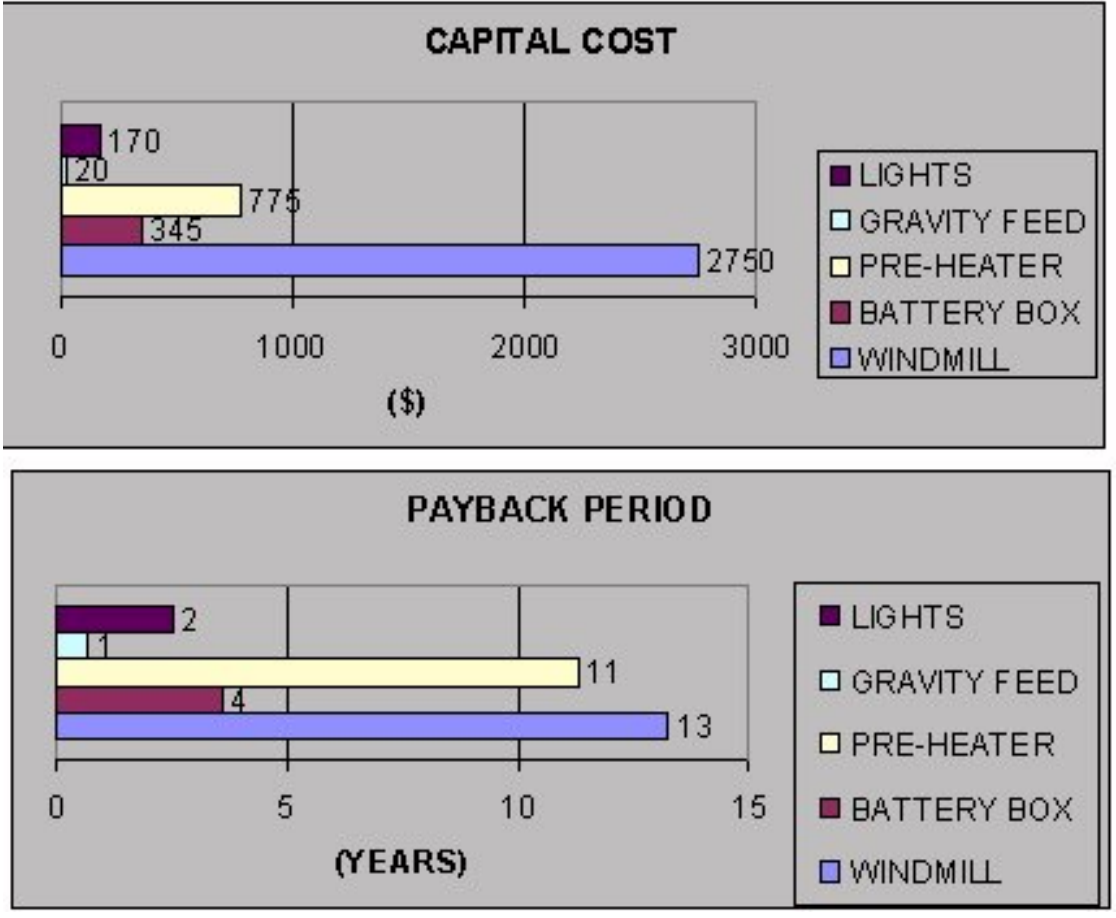

Figure 6. Economics of Power Quantity Upgrades. 
independent of the other options, so the customer may tailor the solution. The team presents the options in sufficient detail for the customer to include her own cost addenda, based in part on intangibles, such as lifestyle. Her decision: adopt all except the preheater / pilot light ignition system. Despite the long payback, the windmill has important indirect advantages for power quality, as explained in the next section of this paper.

Power Quality

The technical problems of the inverter-controller are of a class known as power quality problems. In the case at hand, power quality problems are of two important types: sags and flicker [2]. Starting the pump motor causes a transient reduction in load voltage lasting several cycles, a phenomenon known as a sag. The washer causes regularly repetitive reductions in load voltage, a phenomenon called flicker. Various loads were also inducing current harmonics, though the customer objected to none of their effects.

Two main alternatives appear as solutions to the power quality issue. One choice is to redesign the system, specifying new components having better interaction. The other is to mitigate the system problems by using load management. It is best to compare these alternatives in terms of what improvement each would make at what cost. In either case, an important axiom of power quality work is that power quality problems need not be eliminated, but instead it is sufficient to merely reduce them to the point that the homeowner no longer finds them objectionable [2].

Redesign for Power Quality

The design team proposes the following three options to improve power quality: replace the inverter-controller, include a Variable Frequency Drive (VFD) to reduce the sags, and replace the pumps. To mitigate the flicker caused by the washing machine, the least costly solution requires a larger inverter-controller at a cost of nearly $\$ 7600$. To eliminate starting current transient of the pump motor and the resulting voltage sag, a VFD is the best solution. Unfortunately, a MATLAB simulation of the VFD predicts that it would produce current harmonics sufficient to adversely affect other loads. The VFD itself costs about $\$ 600$ and requires $\$ 400$ for pump modification and a new transformer. The inverter's slow response aggravates the sag problem, but replacing it costs at least $\$ 7600$, as mentioned above. Replacing the AC pressure water pump with a low flow, DC model, fed directly from the batteries, bypasses the inverter. This may reduce the sag to the point that it no longer affects any other load. The cost is the same as the VFD option. Unfortunately, maintenance is more frequent than the AC centrifugal type of pump requires.

The homeowner rejects these options because they are too expensive. Therefore, the team turns its attention to load management as a possible solution to power quality problems.

\section{Load Management for Power Quality}

Load Management can address the problems at hand. The idea of load management is to limit operation of certain system components to certain time periods. Doing so may eliminate problems related to their interaction. Of course, such limits must not cause the system to operate in a manner that the customer finds unacceptable. Load management usually is inexpensive; 
often, it is free. However, success requires a good knowledge of the intangible costs of customer's lifestyle.

A simulation of the system, as shown in Figure 7, reveals that sags stay below $10 \%$ if the diesel generator runs at the same time as the troublesome loads. Flicker tends to be cumulative though not strictly so, e.g., simultaneously running several loads may exceed the $10 \%$ limit recommended by [4]. The family does laundry only once a week, at about the same time each week. Installing a manual switch in the laundry room allows the homeowner to turn on the generator while the washer and dryer operate. Because the inverter-controller creates just enough harmonic voltage to render unreliable

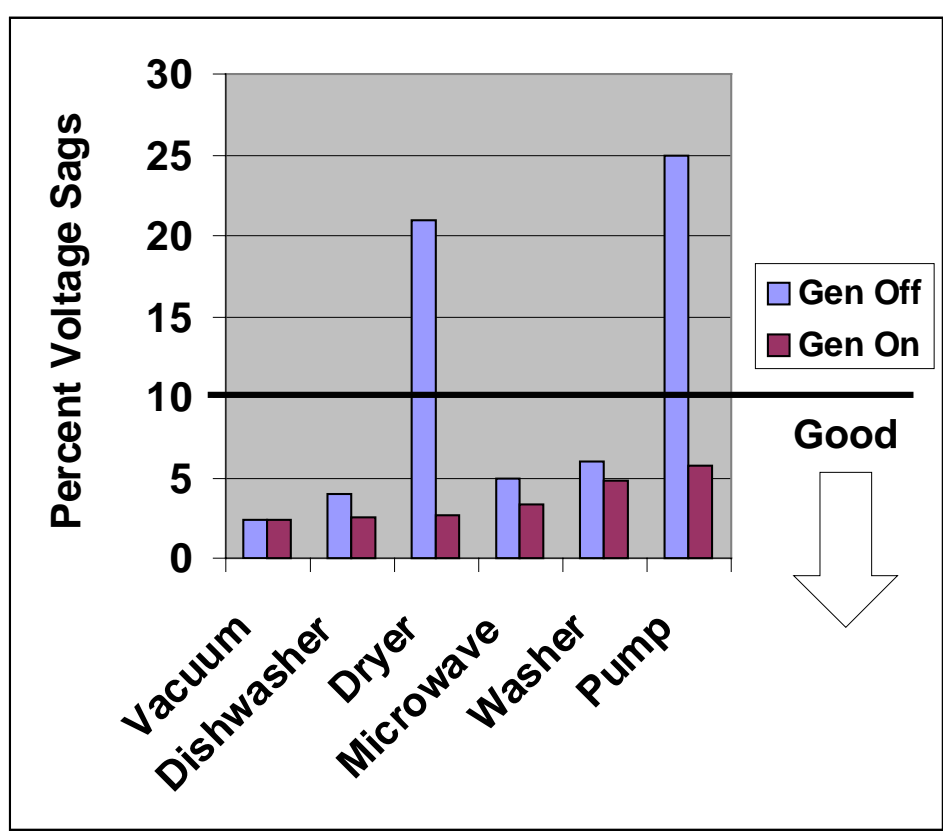

Figure 7. Voltage Fluctuations with Generator OFF or ON. an automatic switch, a manual switch is better. Some simple programming of the weekly battery cycle avoids overcharging the batteries, operating the washer and dryer when the batteries are less than fully charged.

The pump transient requires an integrated mechanical / electrical / human factors solution. The team's Mechanical Engineers recognize that the pump transient's severity is intentionally related to the pressure of the water pressure tank. When the pressure falls below $30 \mathrm{psi}$, the pump starts. Reducing this to 20 psi reduces the starting torque requirement by about $60 \%$. In turn, this reduces the current transient by the square of the reduction in starting torque. Under normal household electrical load, the resulting voltage sag may stay than $10 \%$, even with the generator off. All electronic equipment in the house conforms to ITIC standards [4], which means that a $10 \%$ sag will not adversely affect it. Raising the upper pressure limit from 40 psi to 50 psi makes the pump transient less frequent as well. Relieving the pump of the task of pressurizing the water destined for the bare makes the pump transient even less frequent. Because pump operation becomes quite infrequent, installing a timer to restrict pump operation to the evening hours makes sense. These are the only hours when the family normally operates the lights and sensitive equipment.

Load management cannot mitigate the computer's sensitivity. Even with these innovative load management solutions, the computer remains the lone item sensitive to pump transients. Therefore, the homeowner has a small Uninterruptible Power Supply (UPS), found on sale at a local store. However, the size of this UPS is less than $10 \%$ of the size that any consultant dared recommend to the customer. Load management saves the customer thousands of dollars in UPS cost alone.

Using Load Management techniques improves system performance. It drastically reduces pump transients by working around the problem. Multiple loads may operate on the system without concern for power quality problems. The computer, a sensitive piece of equipment, 
operates without undue risk of damage. By understanding the customer's preferences and habits, the team finds that load management reveals successful ways to overcome power quality problems.

\section{Maintenance}

Inadequate maintenance is the leading cause of failure of isolated power systems. This is particularly true of electrification projects in less-developed nations. Particularly in developed countries, poorly planned maintenance of an isolated power system usually leads to a great deal of needless expense. Therefore, all the team's planning and design is for naught without practical maintenance instructions that are easily understood.

Poor maintenance in isolated power systems has two main causes: inadequate organization of periodic maintenance tasks and inadequate understanding of those tasks by those who perform them. To avoid these problems, the team's Mechanical Engineers create a periodic maintenance schedule for the homeowner. They refine tasks carefully and list the results on a spreadsheet, grouping tasks by intervals of each day, one-month, three-month, six-month, twelve-month, and eighteen-month. Each task has an easy-to-use, color-coded, check box system. They laminate the spreadsheet and attach it as a poster on the wall of the pumphouse. They attach a china marker nearby on a string. They also write out the details of each task and laminated the resulting two pages to the same wall. A sample of the "annual" portion of the tasks is shown in Figure $8 . \quad$ Then the students perform the tasks with the homeowner, to insure that everything is understood. A year later, the system performs reliably. The customer, on her own initiative, seeks out the university president to describe how well the system continues to operate and how easy it is to maintain.

Interdisciplinary Team Design Issues

As an interdisciplinary project, this is one of the more successful. Some observations that merit further study are as follows.

There is only one set of project requirements for reports, presentations, deadlines, and advisor

\begin{tabular}{|l|l|l|}
\hline \hline Every Twelve Months & Date Completed & Date to be Completed \\
\hline \hline 1. Check Batteries & & \\
\hline 2. Battery Equalizing & & \\
Charge & & \\
\hline 3. Give Wind Generator & & \\
Complete Mechanical & & \\
Check & & \\
\hline 4. Check Concentration of & & \\
Coolant & & \\
\hline 5. Check Alternator Drive & & \\
Belt for Wear & & \\
\hline 6. Check Injectors for & & \\
Performance & \\
\hline 7. Renew Air Filter & \\
Element
\end{tabular}

\section{CHECK BATTERIES (Annually)}

Add distilled water if low.

Tighten battery connections.

Remove corrosion and protect terminals.

\section{BATTERY EQUALIZING CHARGE (Annually)}

Cell hydrometer readings differ by more than 20 points

(e.g., 1205 verses 1230), or one cell is weak, give the

battery an equalizing charge.

Figure 8. Sample of Maintenance Instructions.

Proceedings of the 2001 American Society for Engineering Education Annual Conference \& Exposition Copyright Ó 2001, American Society for Engineering Education 
expectations. In this case, they are those of the Mechanical Engineering (ME) Department. The project proceeds in the same flow as all other ME projects. Grades are assigned to $\mathrm{ME}$ standards, though the two EE students receive a grade for completing an $\mathrm{EE}$ course sequence. The project advisor, though an EE professor, effectively becomes an adjunct $\mathrm{ME}$ professor, participating in meetings and decisions for the course. The project is far

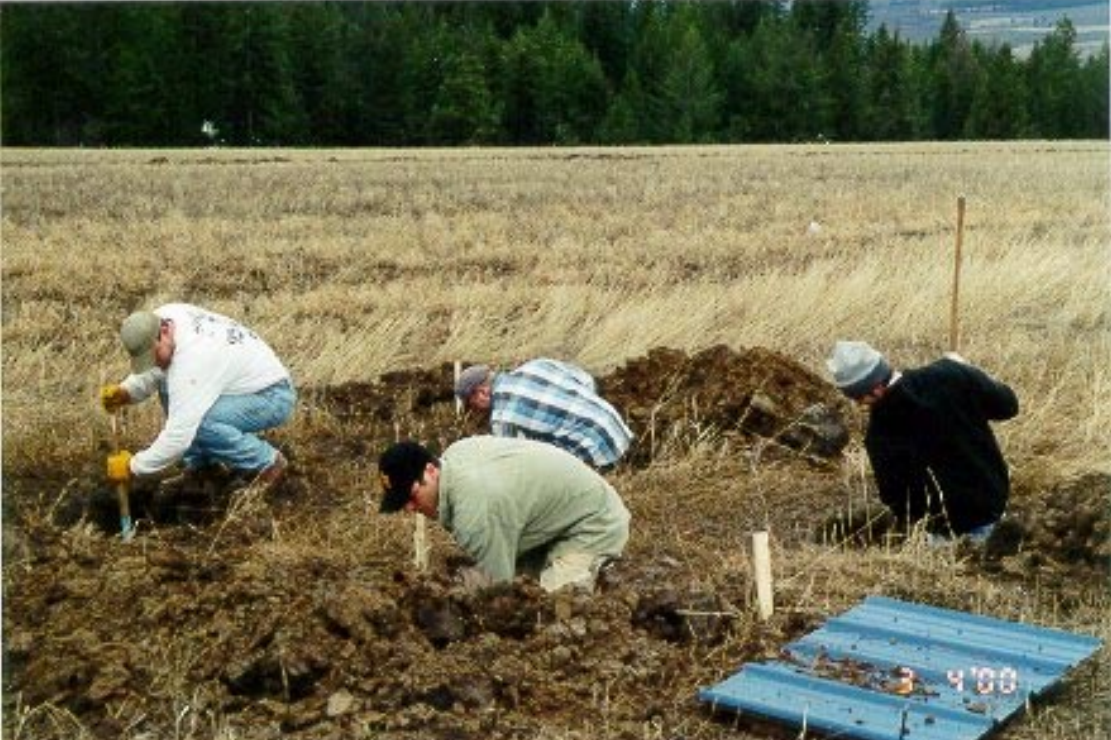

Figure 9. Installing the Wind Generator, (left to right) Troy Stansell, Matt Marks, Frank Albrecht, and Nick Labrum. more effective and organized than any similar interdisciplinary project of this nature attempted at this university in the past.

This unity of requirements in favor of one department appears to give the students a peer group. That peer group is the $42 \mathrm{ME}$ capstone design students. For example, two major progress reports per semester are given in a poster-session format. Peer evaluation is a large part of the grade. Peer pressure to show appropriate progress is definitely evident at these poster sessions. Oral presentations are also peer-evaluated and the same peer pressure is evident. Requiring students to stand with their posters by shift encourages each one to know the projects' details well and to understand the work of cross-disciplinary partners.

For this project, one of the team's Mechanical Engineers is the team leader. His enthusiasm has a great deal to do with the project's success. An "us versus them" mentality never appears because he keeps himself and everyone else too busy to bother. Everyone participates and must know what the others are doing. For example, when building the new windmill tower, all four students wield a spade, as shown in Figure 9. Even creating the website is a four-student task [3]. Nonetheless, having two students of each discipline, according to the students' comments, keeps them from feeling isolated. Of the four students, the two Mechanical Engineers continued into related endeavors. Frank Albrecht, the project team leader, found employment in renewable resources. Matt Marks continued into graduate school; his research has important aspects in design of energy systems. The two Electrical Engineers found employment with in the semiconductor process industry.

This project is a two-semester one. The homeowner paid \$2500 and major hardware costs. The $\$ 2500$ covers small expenses and the costs of recruiting the next year's projects.

\section{Conclusions}

In this project, an interdisciplinary team of Mechanical and Electrical Engineering students redesigns an isolated electric power system. The team performs real, solid engineering in a broad sense. Creative approaches to energy management are an important contribution of this project. First, the team investigates whether the project is feasible, examining the problem and 
the customer's ability to fund a solution. Second, upon determining that this is indeed feasible, they create a technically sound design. Third, using a graduated cost-benefit formulation, they present their design in a way that allows the customer to tailor the solution, including the intangible human factors that are quite difficult to assess, but so important. Fourth, the students build and test their design. Fifth, they establish a user-friendly maintenance system that insures that their work that pleases the customer and makes it probable that their design will please the homeowner for many years.

\section{References}

[1] J. Peterson and H. Hess, "Feasibility, Design and Construction of a Small Hydroelectric Power Generation Station as a Student Design Project,” 1999 ASEE Annual Conference, Charlotte, NC, Session 2533.

[2] R. Dugan, M. McGranahan, and W. Beaty, "Electric Power Systems Quality," (New York: McGraw-Hill, 1996).

[3] F. Albrecht, T. Stansell, M. Marks, and N. Labrum, Department of Mechanical Engineering, University of Idaho, http://www.uidaho.edu/engr/ME/sr_des/powerbrokers/, created April 1999, read 5 January 2001.

[4] “ITIC Curve," Information Technology Industry Council, http://www.itic.org/technical/iticurv.pdf , created April 2000, read 6 January 2001.

\section{HERB HESS}

Herb Hess received the PhD degree in Electrical and Computer Engineering from the University of WisconsinMadison in 1993. From 1983-1988, he served on the faculty of the United States Military Academy. He joined the University of Idaho in 1993, where he is Associate Professor of Electrical and Computer Engineering. He received the Best Paper Overall Award for the 1999 ASEE Annual Conference. His interests are in power electronic converters electric machine drive systems, and power quality. 